\title{
Possible inhibition of hydroxy methyl glutaryl CoA reductase activity by nicotinic acid and ergosterol: as targeting for hypocholesterolemic action.
}

\author{
Said S. Moselhy ${ }^{1,2,3,6}$ Kamal IH ${ }^{1,6}$,Taha A. Kumosani ${ }^{1,2,4}$, Huwait EA ${ }^{1,2,4}$
}

\author{
1. Biochemistry Department, Faculty of science, King Abdulaziz University. \\ 2. Experimental biochemistry unit, King Fahad Medical Research center (KFMRC). \\ 3. Bioactive Natural Products Research Group. \\ 4. Production of bio-products for industrial applications Research group, \\ 5Vitamin D Research group King Abdulaziz University P.O. Box 21424, Jeddah, Saudi Arabia. \\ 6. Biochemistry department, faculty of science, Ain Shams University, Cairo, Egypt.
}

\begin{abstract}
Objective: Coronary artery diseases including atherosclerosis is considered as commonest problem worldwide. Ergosterols are the main components of vegetable oils and nuts. The objective of this study was to evaluate the potential hypoplipidemic and hypocholesterolemic effects of ergosterol in combination with niacin in rats fed high fat diet (HFD).

Methods: Eighty male albino rats were included in this study divided into two main groups: Group I: Normal rats fed standard diet treated with either niacin $(8.5 \mathrm{mg} / \mathrm{kg} \mathrm{b.w})$ or ergosterol $(100 \mathrm{mg} / \mathrm{Kg}$ b.w) or both. Group II; rats fed HFD treated with either niacin $(8.5 \mathrm{mg} / \mathrm{kg}$ b.w) or ergosterol $(100 \mathrm{mg} / \mathrm{Kg}$ b.w) or both The feeding and treatment lasted for 8 weeks. Results: A significant elevation in the levels of total cholesterol, triacylglycerol, VLDL-c, LDL-c and atherogenic factor $(p<0.001)$ in rats fed on HFD compared with normal control while HDL-c was significantly reduced in HFD rats compared with control group. Supplementation of diet with niacin or ergosterol or combined exerts improvement in the studied parameters by lowering triacylglycerol, total cholesterol, LDL-c and atherogenic factor and elevate HDL-c near to the value of control. Niacin combined with ergosterol were effective in the reduction of hydroxy methyl glutaryl-CoA reducatase (HMGCoA) compared with control $(\mathrm{p}<0.001)$. The combined effect was more potent than individual alone.

Conclusion: Utilization of niacin and ergosterol may prevent the hypercholesterolemia and incidence of coronary heart diseases. These functional foods act as nutriceutical as dyslipidemics.

Keywords: Nicotinic acid, cholesterol, ergosterol.

DOI: http://dx.doi.org/10.4314/ahs.v16i1.42

Cite as: Moselby SS, Kamal IH, Kumosani TA, Huwait EA. Possible inbibition of bydroxy methyl glutaryl Co $A$ reductase activity by nicotinic acid and ergosterol: as targeting for bypocholesterolemic action. Afri Health Sci. 2016;16(1): 319-324. http:/ / dx.doi.org/ 10.4314/ ahs.v16i1.42
\end{abstract}

\section{Introduction}

Cholesterol is non-calorigenic nutrient due to lack of enzymes that metabolize it. It is an essential for plasma membranes structure and formation of lipoproteins, aldosterone, bile salts, and cholicalciferol ${ }^{1}$.Cholesterol in the body may be exogenous (from diet) or endogenous which synthesized from active acetate in the liver, testis, and ovary and controlled by the key enzyme hydroxy methyl glutaryl-CoA reductase (HMGCoA Rase). Blood cholesterol level determined by the balance be-

\section{Corresponding author: \\ Said S. Moselhy, \\ Biochemistry department, Faculty of Science \\ King Abdulalziz University, \\ Jeddah, Saudi Arabia \\ Email.moselhy6@hotmail.co}

tween its rate of synthesis and rate of excretion. The liver is the only organ can eliminate the cholesterol by excretion via the bile ${ }^{2}$.

Coronary artery diseases (CAD) including atherosclerosis considered as the commonest cause of death worldwide. Other risk factors including smoking, hypertension, lifestyle, diabetes and fast foods. Hypercholesterolemia especially elevated LDL-c and decreased HDL-c are the most valuable markers for $\mathrm{CAD}^{3}$. Atherosclerosis is indicated by the appearance of initial changes known as plaques. These plaques are made of lipid cores (cholesterol) surrounded by fibroid caps ${ }^{5}$. A clear cut correlation was found between dietary cholesterol and CAD by several previous studies in animal models and human. The risk for CAD is approximately three fold in diabetes mellitus compared with normal controls ${ }^{4}$. 
Nicotinic acid or niacin is is converted to important co-enzymes NAD+, or NADP+. These co-enzymes act as a hydrogen carrier involved in oxidation reduction reactions during metabolism of macromolecules as carbohydrate, lipids and proteins ${ }^{5}$.

Ergosterols are the main components of vegetable oils, nuts, cereal products, fruit and berries. The common types are $\beta$-sitosterol, campesterol and stigmasterol ${ }^{6}$. Phytosterol was found to act as anticancer and antioxidant agent. It was found in several studies that intake of foods as margarine or yoghurt supplemented with plant stanol lower serum total cholesterol and LDL-c. This is the principle hypocholesterolemic effect of drugs and exert a significance effect in lowering $\mathrm{CAD}^{7}$. There are different hypocholestrolemic agents available, these drugs act by different mechanisms. Efficacy relies on the lipid level of the subjects. These drugs have adverse effects varied from one to another. Thus, researches are promising to explore novel drugs that are more efficacies and more safe.

This study was designed to evaluate the potential hyoplipidemic and hypocholesterolemic effect of ergosterol in combination with nicotinic acid in rats. For this purpose, this study aims to deduce a new regime for protection against $\mathrm{CAD}$.

\section{Materials and methods \\ Animals}

This study was carried out on a total of 80 adult male albino rats weighing 100-120 g. The animals were housed in steel cages and left for one week before starting the experiment. The commercial diet supplemented with 2 $\%$ cholesterol, and $0.4 \%$ sodium cholate considered as high cholesterol diet ${ }^{8}$.The handling of animals according to ethical committee of the university.

Rats were grouped into two main groups (each 40 rats) as following: Group I: normal rats fed a standard diet and divided into 4 subgroups: Group Ia; normal untreated. Group Ib: rats treated orally with niacin (8.5 $\mathrm{mg} / \mathrm{kg}$ b.w). Group Ic: rats treated orally with ergosterol $(100 \mathrm{mg} / \mathrm{Kg}$ b.w.). Group Id. rats treated orally with niacin (8.5 mg / kg b.w.) and ergosterol (100 mg/ $\mathrm{Kg}$ b.w.). Group II: rats fed high HFD (1\% cholesterol $(\mathrm{w} / \mathrm{w})$ and $0.2 \%$ sodium cholate $(\mathrm{w} / \mathrm{w})$ were well mixed with the finely-ground commercial diet) subdivided into 4 subgroups. Group IIa ; HFD untreated.
Group IIb: HFD treated orally with niacin $(8.5 \mathrm{mg} /$ $\mathrm{kg}$ b.w.) Group IIc: HFD rats treated orally with ergosterol $(80 \mathrm{mg} / \mathrm{Kg}$ b.w). Group IId : HFD treated orally with niacin ( $8.5 \mathrm{mg} / \mathrm{kg}$ b.w.) and ergosterol $(80 \mathrm{mg} / \mathrm{Kg}$ b.w.).The doses of ergosterol and niacin will given according to Takaku et $\mathrm{a}^{12}$.Treatment was started on the day starting feeding high cholesterol and continued for 8 weeks. Rat were fasted for $12 \mathrm{hr}$ and anesthetized with $10 \%$ thiopental. Blood samples were collected and sera were separated by centrifugation and stored at $-80^{\circ} \mathrm{C}$ until analysis. Liver was removed, rinsed from blood. Part of it was placed in sulphuric acid for total lipid assay and the remainder of liver will stored in at $-80^{\circ} \mathrm{C}$ until analysis.

\section{Biochemical assays}

Serum total cholesterol, triacylglycerol, total lipid lipoproteins (VLDL-c, LDL-c and HDL-c) were estimated by colorimetric methods using kits from BIOLINE company (UK). Atherogenic index was calculated as following.

Atherogenic index $=\mathrm{LDL}+\mathrm{VLDL} / \mathrm{HDL}$

\section{Determination of liver microsomal HMGCoA re- ductase}

One gram of liver was placed in $5 \mathrm{ml}$ cold buffer $\left(-4^{\circ} \mathrm{C}\right)$ at $\mathrm{pH}$ 7.4. The buffer contained $0.1 \mathrm{M}$ triethanolamine. $\mathrm{HCl}, 0.02 \mathrm{M}$ EDTA, and 2.0mM dithiothreitol, homogenized using glass homogenizer. The homogenate was centrifuged for $10 \mathrm{~min}$ at $12,000 \mathrm{~g}$ to remove mitochondria. Supernatant was centrifuged at $20,000 \mathrm{~g}$ for $30 \mathrm{~min}$. The microsomes obtained were used for the assay of protein concentration and HMGCoA reductase. For assay $0.5-1 \mathrm{mg}$ of microsomal protein, 100 nmoles of HMG CoA, and $2 \mu$ moles of NADPH, 2 units of glucose-6-phosphate dehydrogenase, and $3 \mu$ moles of glucose-6-phosphate. These components are added to $0.8 \mathrm{ml}$ of $0.1 \mathrm{M}$ triethanolamine-0.02 M EDTAbuffer at $\mathrm{pH} 7.4$ without dithiothreitol. The concentration of monothiol is determined by reacting DTNB with the reaction mixture in a cuvette placed in a recording spectrophotometer?.

The unit of HMGCoA reductase is defined as the micromole of mevalonate produced per unit of enzyme per second.

\section{Statistical analysis}

Data will be expressed as means \pm SD and t-test, $\mathrm{p}$-value and Man-watany correlation will performed using SPSS version ${ }^{12}$. 


\section{Results}

Table (1) revealed the impact of niacin and ergosterol on normal rats fed normal diet. It was found that, normal rats supplemnteed with niacin, ergosterol or combined showed a significant reduction in lipid profile including TG, total cholesterol and LDL-c while a significant increase in HDL-c compared with control group $(\mathrm{p}<0.01)$.

Table (1): Serum levels of total-cholesterol, triacylglycerol, HDL-c, LDL-c, VLDL-c and atherogenic factor in normal rats supplemented with niacin and ergosterol (Mean+SD)

\begin{tabular}{|c|c|c|c|c|}
\hline $\begin{array}{r}\text { Groups } \\
\text { Parameters }\end{array}$ & Normal & Normal + niac & Normal+Erg & $\mathrm{N}+$ niac $+\mathrm{ERG}$ \\
\hline $\begin{array}{r}\text { Body weght }(\mathrm{gm}) \\
\text { Mean }+\mathrm{SD}\end{array}$ & $295+11.7$ & $309+50$ & $282+26$ & $293+15$ \\
\hline $\begin{array}{r}\text { T-cholesterol }(\mathrm{mmol} / \mathrm{l}) \\
\text { Mean }+\mathrm{SD}\end{array}$ & $1.85+0.16$ & $1.73+0.20$ & $1.51+0.16$ & $1.57+0.13$ \\
\hline $\begin{array}{r}\text { Triacyglycerol }(\mathrm{mmol} / \mathrm{l}) \\
\text { Mean }+\mathrm{SD}\end{array}$ & $0.9+0.14$ & $0.8+0.03$ & $0.71+0.03$ & $0.77+0.02$ \\
\hline $\begin{array}{r}\text { HDL-c }(\mathrm{mmol} / \mathrm{l}) \\
\text { Mean }+\mathrm{SD}\end{array}$ & $0.44+0.03$ & $0.52+0.08$ & $0.50+0.07$ & $0.51+0.06$ \\
\hline $\begin{array}{r}\text { LDL-c }(\mathrm{mmol} / \mathrm{l}) \\
\text { Mean +SD }\end{array}$ & $1.0+0.11$ & $1.2+0.19$ & $1.1+0.15$ & $1.1+0.13$ \\
\hline $\begin{array}{r}\text { VLDL-c }(\mathrm{mmol} / \mathrm{l}) \\
\text { Mean +SD }\end{array}$ & $0.21+0.02$ & $0.22+0.02$ & $0.18+0.03$ & $0.17+0.01$ \\
\hline $\begin{array}{r}\text { Aatherogenic factor } \\
\text { Mean +SD }\end{array}$ & $0.081+0.01$ & $0.12+0.02$ & $0.033+0.01$ & $0.01+0.001$ \\
\hline
\end{tabular}

In table (2), Rats fed high fat diet showed that, a significant elevation in the levels of total cholesterol, triacylglycerol, , VLDL-c, LDL-c and atherogenic factor $(\mathrm{p}<0.001)$ in rats fed on HFD compared with normal control while HDL-c was significantly reduced. Sup- plementation of diet with niacin or ergosterol or combined exerts improvement in the studied parameters by lowering triacylglycerol, total cholesterol, LDL-c and atherogenic factor and elevating HDL-c till it reached near to the value of control as compared with HFD fed rats $(\mathrm{p}<0.001)$. 
Table (2): Serum levels of total-cholesterol, triacylglycerol, HDL-c, LDL-c, VLDL-c and atherogenic factor it hypercholesterolemic rats treated with niacin and ergosterol (Mean $\underline{+} \mathrm{SD})$

\begin{tabular}{|c|c|c|c|c|}
\hline $\begin{array}{c}\text { Groups } \\
\text { Parameters }\end{array}$ & HFD & $\mathrm{HFD}+\mathrm{Nia}$ & $\mathrm{HFD}+\mathrm{ERGO}$ & $\mathrm{HFD}+\mathrm{Nia}+\mathrm{ERG}$ \\
\hline $\begin{array}{r}\text { Body weght } \\
\text { Mean+SD }\end{array}$ & $350+33$ & $305+29$ & $291+32$ & $275+19^{a}$ \\
\hline $\begin{array}{r}\text { T-cholesterol }(\mathrm{mmol} / \mathrm{l}) \\
\text { Mean+SD }\end{array}$ & $2.82+0.12$ & $2.4+0.21$ & $1.95+0.21, \mathrm{ab}$ & $1.9+0.17 \mathrm{a}, \mathrm{b}$ \\
\hline $\begin{array}{r}\text { Triacyglycerol }(\mathrm{mmol} / \mathrm{l}) \\
\text { Mean+SD }\end{array}$ & $1.8+0.52$ & $1.6+0.08$ & $1.5+0.22$ & $1.4+0.05$ \\
\hline $\begin{array}{r}\text { HDL-c(mmol/l) } \\
\text { Mean+SD }\end{array}$ & $0.41+0.42$ & $0.42+0.07$ & $0.43+0.05$ & $0.49+0.06$ \\
\hline $\begin{array}{r}\text { LDL-c }(\mathrm{mmol} / \mathrm{l}) \\
\text { Mean+SD }\end{array}$ & $1.9+0.11$ & $1.92+0.12$ & 1. $8 .+0.11$ & $1.76+0.14 a, b$ \\
\hline $\begin{array}{r}\text { VLDL-c }(\mathrm{mmol} / \mathrm{l}) \\
\text { Mean+SD }\end{array}$ & $0.1+0.009$ & $0.1+0.01$ & $0.11+0.04$ & $0.1+0.01$ \\
\hline $\begin{array}{r}\text { Atherogenic factor } \\
\text { Mean }+ \text { SD }\end{array}$ & $0.54+0.08$ & $0.41+0.02$ & $0.36+0.01$ & $0.21+0.07 \mathrm{a}, \mathrm{b}$ \\
\hline
\end{tabular}

HFD: High fat diet $p$ : compared with control group. $p^{*}$ : compared with HFD NS: non signifficant $p<0.05$ was considered a significant Nia: Niacin ERG:ergosterol

Results obtained in Fig 1. indicated that niacin , ergosterol and combined were effective in the reduction of
HMGCoA reductase compared with control $(\mathrm{p}<0.001)$. The combined effect was more potent than individual alone.

Fig 1: The activity of HMGGoNRase in nomal and hypercholestemlemic rats treated with niacin and ergosterol

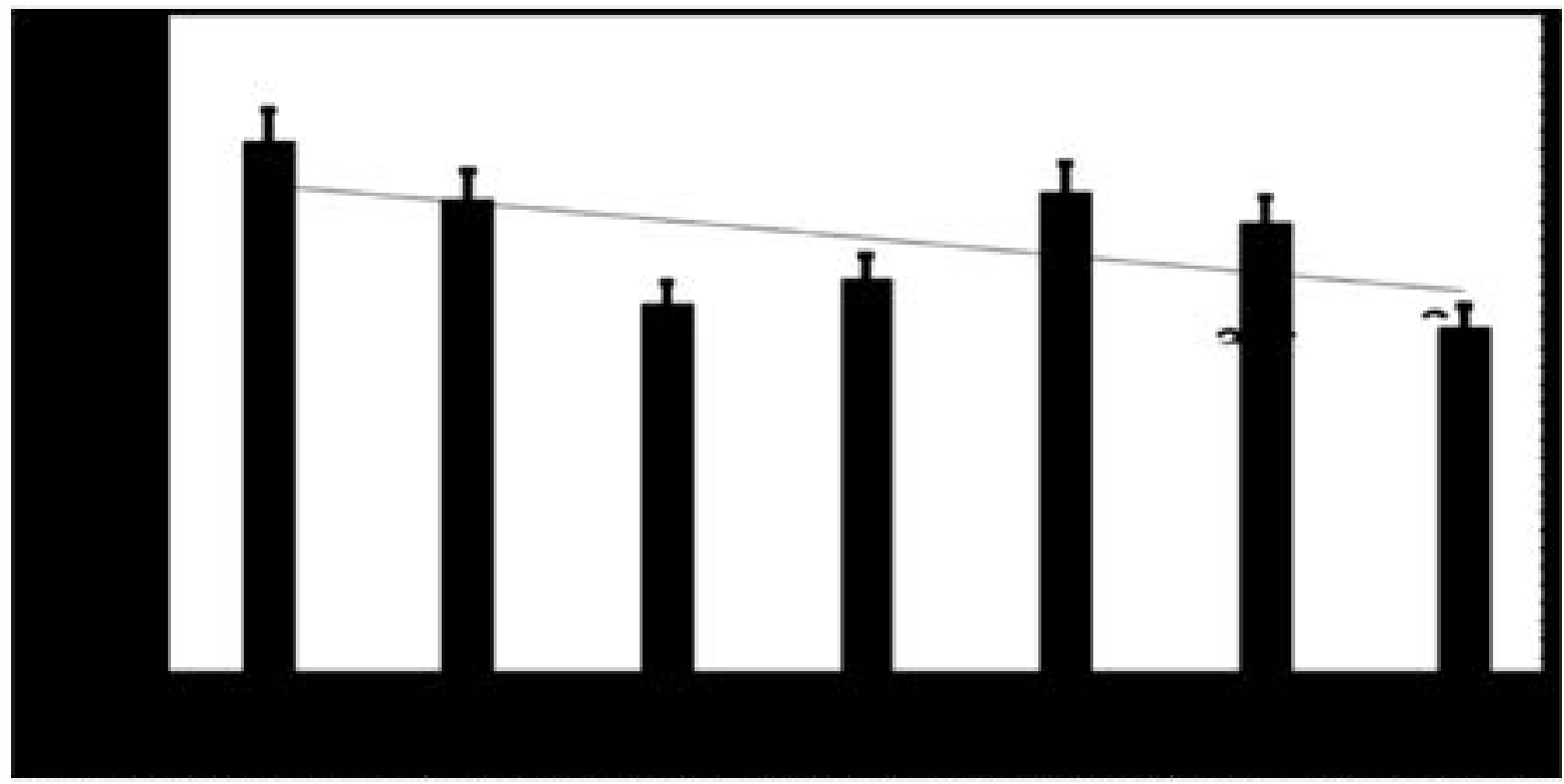

Group Ia; normal untreated. Group Ib: normal with niacin $(8.5 \mathrm{mg} / \mathrm{kg}$ b.w). Group Ic: normal with ergosterol (100 mg/Kg b.w). Group Id. normal with niacin $(8.5 \mathrm{mg} / \mathrm{kg} \mathrm{b.w})$ and ergosterol (100 mg/Kg b.w).Group IIa; HFD untreated. Group IIb: HFD with niacin $(8.5 \mathrm{mg} / \mathrm{kg}$ b.w) Group IIc: HFD rats with ergosterol $(80 \mathrm{mg} / \mathrm{Kg}$ b.w).Group IId: HFD with niacin (8.5 mg $/ \mathrm{kg} \mathrm{b.w})$ and ergosterol (80 mg/Kg b.w). 


\section{Discussion}

The HMG CoA reductase catalyses the rate limiting step in cholesterol synthesis ${ }^{10}$. The activity of HMG CoA reductase is regulated by the nutritional and hormonal state of animals. Feedback inhibition of cholesterol formation is mediated by the activity of HMG CoA reductase. Many chemically synthesized compounds called statins, have also been developed as effective cholesterol lowering agents through the inhibition of HMG CoA reductase. However, most hypocholesterolemic agents have been found to possess adverse effects, including rashes, gastrointestinal, hyperuricemia, hyperglycemia ${ }^{11}$.

In the present study supplementing rats with niacin $\mathrm{O}$, LDL-c and TG compared to control rats. Niacin was found to lower plasma total cholesterol and triglyceride levels by lowering VLDL-c and LDL-c levels ${ }^{12}$. On the other hand it elevates HDL-c levels. Plant sterol possesses the ability to lower effect in a wide range of food products. The cholesterol and LDL-C lowering effect of ergosterol as well as safety of daily consumption of plant source was in accordance with different studies ${ }^{13}$. The most recent is evidence that intakes of ergosterol result in an enhanced decrease in LDL-c level comparable to that obtained by statins. The lowering of LDL-C was higher and is feasible as a range of food products are commercially available for consumption. LDL-c lowering effect contributes to beneficial effects in reducing the risk of cardiovascular diseases ${ }^{14}$. The decrease in the LDL-c level due to consumption of plant stanols in high doses (about $9 \mathrm{~g}$ ) is of similar magnitude to that achieved by drugs lowering cholesterol via partly blocking cholesterol absorption ${ }^{15}$.

Changes in HMG-CoA reductase activity are accompanied to changes in the rate of cholesterol synthesis, suggesting the inhibition of HMG-CoA reductase is effective in lowering plasma cholestero ${ }^{16}$.

On the basis of the present study, a significant LDL-c lowering effect can be done by a dietary supplementation of ergosterol. However, there was a dose-range effect of plant sterols and stanols on serum LDL-c lowering and it is reported that plant stanols showed a continuous dose-response in serum LDL-c lowering, whereas no further serum LDL-c was apparent with plant sterols at daily intakes exceeding $2 \mathrm{~g} / \mathrm{day}^{17,18}$.

Three of the studies with high daily plant stanol intake also reported serum plant stanol and sterol con- centrations. Assmann et al., ${ }^{19}$ demonstrated that a daily intake of $8.8 \mathrm{~g}$ plant stanols decreased cholesterol absorption markers .Similarly, Mensink et al., ${ }^{20}$ showed continuous decrease in plasma sitosterol and campesterol concentrations with 3, 6 and $9 \mathrm{~g}$ intakes of plant stanols in comparison to controls. With increasing plant stanol intake, the cholesterol absorption was reduced ${ }^{21}$. Nguyen $^{22}$ reported a $40 \%$ lower campesterol and 50\% lower sitosterol levels after daily consumption of $10 \mathrm{~g}$ of plant stanols.

The present study showed the role of niacin combined with ergosterol in reducing the cholesterol level by inhibiting the HMG CoA reductase activity. This finding can result in developing a nutraceutical agent and can be used in management of disorders of cholesterol for controlling the dyslipidemia.

\section{Conclusion}

Daily utilization of niacin and ergosterol may protect against hypercholesterolemia and decrease incidence of coronary heart diseases. These functional foods act as nutriceutical as dyslipidemics.

\section{Acknowledgment}

This work was funded by the Deanship of Scientific Research (DSR), King Abdulaziz University, Jeddah, under grant No.(130-164-D1435).The authors therefore acknowledge with thanks, DSR technical and financial support.

\section{References}

1. Assmann G, Schriewer H, Schmitz G, Hagele EO (1983): Quantification of high density lipoprotein cholesterol by precipitation with phosphotungstic acid/ $\mathrm{MgCl}$. Clin Chem, 29:2026-2030.

2. Chern J, Tao P, Wang K, Gutcait A, Liu S, Yen M, Chien S, Rong J(1998) : Studies on quinazolines and 1,2, 4-benzothiadiazine 1,1- dioxides. Synthesis and pharmacological evaluation of tricyclic fused quinazolines and 1,2,4-benzothiadiazine 1,1,-dioxides as potential alpha 1-adrenoceptor antagonists. J Med Chem, 41:31283141.

3. Devlin $\mathrm{T}(1995)$ : Textbook of biochemistry with clinical correlations 3rd edition. New York, Wiley-Liss Inc;:376-381.

4. Freidwald WT, Levy RJ, Fredrickson DS (1972): Estimation of the concentration of the preparative ultracentrifuge. Clin Chem, 18:499-509.

5. Fuster V, Alexander PW, O'Rourke RA, Roberts R, King SB, Wellens HJ[O1] (2001): Atherogenesis and its 
determinants. In Hurst's the heart Volum 3. 10th edition. New York, Mc Graw-Hill:1065.

6. Habib NS, Ismail KA, El-Tombary AA, Abd El-Aziem T (2000): Antilipidemic agents, Part IV: Synthesis and antilipidemic testing of some heterocyclic derivatives of hexadecyl and cyclohexyl hemisuccinate esters. Pharmazie, 55:495-499.

7. Jacobs NJ, Van Denmark PJ: The purification and properties of the alpha-glycerophosphate-oxidizing enzyme of Streptococcus faecalis.

8. Jantova S, Urbancikova M, Maliar T, Mikuldsova M, Rauko P, Cipak L, Kubikova J, Stankovsky S, Spirkova K (2001): Biological activity of some 4-anilinoquinazolines: cytotoxic, genotoxic and antiprotease effects, induction of necrosis and changes of actin cytoskeleton. Neoplasm, 48:52-60.

9. John M (2006). How does nicotinic acid modify the lipid profile? European Heart Journal Supplements, 8 (Supplement F), F54-F59.

10. Kerscher L, Schiefer S, Draeger B, Maier J, Ziegenhorn J (2006): Precipitation methods for the determination of LDL-cholesterol. Clin Biochem 1985, 18:118-125. 11. Knight JA, Anderson S, Rawle JM (1972): Chemical basis of the sulfophospho- vanillin reaction of estimating total serum lipids. Clin Chem, 18:199-204.

12. Koschinsky ML, Marcoina SM (2003): The relationship between lipoprotein alpha and the complications of diabetes mellitus. Acta Diabet, 40:65-76.

13. Krentz AJ (2003): Lipoprotein abnormalities and their consequences for patients with type 2 diabetes. Diabetes Obes Metab, 5:19-27.
14. Kunes J, Bazant J, Pour M, Waisser K, Slosarek M, Janota J (2000): Quinazoline derivatives with antitubercular activity. IL Farmaco, 55:725-729.

15. Magnus NA, Confalone PN, Storace L, Patel M, Wood CC, Davis WP, Parsons RL(2003): General scope of 1,4-Diasteoselective additions to a $2(3 \mathrm{H})$ - quinazolinone: Practical preparation of HIV therapeutics. J Org Chem, 68 :754-61.

16. McNamara DJ: Dietary cholesterol and atherosclerosis. Biochim Biophys Acta 2000, 1529:310-320.

17. Nguyen, L. B., S. Shefer, G. Salen, G. C. Ness, G. S. Tint, F. G. Zaki, and I. Rani (1990). A molecular defect in hepatic cholesterol biosynthesis in sitosterolemia with xanthomatosis. J Clin Invest 86: 923-931.

18. Santagati A, Modica M, Santagati M, Cutuli VM, Mangano NG, CarusoA (2000): Synthesis and pharmacological screening of 1, 3, 4-thiadiazino2,3-bquinazoline derivatives. Pharmazie, 55: 737-739.

19.Takeshi T, Yoshiyuki $\mathrm{K}$ and Hiromichi O (2001). Isolation of an Antitumor Compound from Agaricus blazei Murill and Its Mechanism of Action. Nutr. 131: 1409-1413.

20. Takeshi Takaku, Yoshiyuki Kimura and Hiromichi Okuda (2001). Isolation of an Antitumor Compound from Agaricus blazei Murill and Its Mechanism of Action1American Society for Nutritional Sciences;1409-1414.

21. Trinder P (1969): Determination of glucose in blood using glucose oxidase with an alternative oxygen receptor. Ann Clin Biochem, 6:24-28.

22. Zlatkis A, Zak B, Boyle AJ (1953): A new method for the direct determination of serum cholesterol. J Lab Clin Med, 41:486-92. 